\title{
Comparative biology of the crab Goniopsis cruentata: geographic variation of body size, sexual maturity, and allometric growth
}

\author{
José Jonathas Pereira Rodrigues de Lira ${ }^{1,2}$ Tereza Cristina dos Santos Calado ${ }^{1}$ • \\ Carla Ferreira Rezende ${ }^{2} \cdot$ José Roberto Feitosa Silva ${ }^{2}$
}

Received: 29 January 2015/Revised: 11 August 2015/Accepted: 17 August 2015/Published online: 22 August 2015

(C) Springer-Verlag Berlin Heidelberg and AWI 2015

\begin{abstract}
Geographic variation of phenotypic traits is common across species and is often associated with variation in environmental conditions. Here, we found larger bodies and larger size at maturity in a northward, lower latitude population of the crab Goniopsis cruentata, which inhabits a hotter, drier environment in comparison with a southward, higher latitude population. Furthermore, the juvenile male gonopods grow more relative to body size in the population characterized by maturation at a smaller size. In contrast, the female abdomen widens at a higher rate among the late maturing population. These results provide further evidence that local environmental conditions play a role in phenotypic variation between populations inhabiting different latitudes. Moreover, they also show that variation in size at maturity and body size can lead to divergent allometric patterns of sexual characteristics that can have a sex-specific response.
\end{abstract}

Keywords Phenotypic variation - Population biology · Allometry $\cdot$ Crustacea $\cdot$ Mangrove

Communicated by L. Gutow.

José Jonathas Pereira Rodrigues de Lira

lirajjpr@gmail.com

1 Laboratórios Integrados de Ciências do Mar e Naturais, Universidade Federal de Alagoas (UFAL), Av. Aristeu de Andrade, 452, Farol, Maceió, Alagoas 57051-090, Brazil

2 Laboratório de Histologia e Reprodução Animal, Departamento de Biologia, Universidade Federal do Ceará, Av. Humberto Monte, s/n, Campus do Pici, Fortaleza, Ceará 60455-900, Brazil

\section{Introduction}

Life-history theory relies on a set of coadapted traits that evolve to maximize offspring survival, termed 'fitness maximization' (Stearns 1976). A direct consequence of this optimization is that populations tend to evolve to fit their own habitat, which often leads to differences in biological traits among populations (Olalla-Tárraga et al. 2009; Monaco et al. 2010). This is often the case for species with broad geographic ranges in which latitudinal clines are observed.

Latitudinal clines result in graded environmental conditions that can result in differences at either end of the spectrum, which is often demonstrated to affect biological traits in a myriad of species (Monaco et al. 2010; Lardies et al. 2010; Terossi et al. 2010). Indeed, several studies have shown that body size within a species tends to increase as the environmental temperature moves from warm to cold across a broad geographic scale (Angilletta et al. 2004a, b; Olalla-Tárraga et al. 2009). While other factors (e.g., heat balance, water availability, desiccation risk, productivity, habitat availability-Olalla-Tárraga et al. 2009, and food availability-Gardner et al. 2011) could potentially explain this variation, it still suggests that local environmental conditions can influence biologically relevant traits. For example, larger body sizes tend to be selected for under high desiccation risk because the smaller surface area in relation to body volume reduces vulnerability to desiccation (Atkinson 1994; Gardner et al. 2011; Olalla-Tárraga et al. 2009; Allen et al. 2012).

Body size virtually influences all physiological and fitness-related traits of an organism (Kingsolver and Huey 2008; Gardner et al. 2011). As such, its variation is likely to be associated with variations in other biological features. For instance, body size is often recognized as being highly 
correlated with size at maturity (Stearns 1989; Hartnoll 2006) such that smaller animals often achieve maturity at smaller sizes (Angilletta et al. 2004b; Shimada et al. 2011). Body size has also been associated with latitudinal variation and sexual maturity in many species of crustaceans in which larger bodies and larger size at maturity occur in higher latitudes, i.e., cooler environments (Hines 1989; Monaco et al. 2010; Queirós et al. 2013). This might suggest that a positive selective pressure exists for delayed maturation in cooler environments.

These variations in body size and sexual maturity are likely to indirectly affect relative growth, the rate of development of one body part relative to the whole body (Hartnoll 1982). In crustaceans, this has been shown to occur because maturity is tightly associated with sets of morphological and physiological changes in organisms (Hartnoll 1982, 1985; Émond et al. 2010). Such changes are often observed to affect reproductive processes through changes in primary and secondary sexual characters (Hartnoll 1982; Émond et al. 2010; Lira and Calado 2013). For example, the primary sexual character of males, the gonopods, grows faster relative to the whole body in the juvenile phase but slower or at the same rate in the adult phase (Hartnoll 1982; Émond et al. 2010). This is suggested to be a response to stabilizing selection that allows males to copulate with a wide size range of females, in light of the close association between the morphology of the gonopods and the female genitalia (Eberhard et al. 2009; Émond et al. 2010). A secondary sexual character of females, the abdomen, commonly grows faster than body size throughout ontogenetic development (Hartnoll 1982; Lira and Calado 2013) as a response to directional selection for a wider abdomen which provides increased space for incubation of embryos (Hartnoll 1982; Émond et al. 2010). This relationship between sexual maturity and sexual characters can result in the growth of reproductive structures being influenced by the period of time an individual takes to reach a minimum reproductive size. Thus, it is reasonable to expect that the relative growth of reproductive structures relative to body size is greater when maturity is attained earlier. We might expect that if body size and maturity vary between populations under different environmental conditions, the allometric growth of reproductive structures will as well. However, to our knowledge, studies that have attempted to test such variation are rare (but see Hirose et al. 2013).

Here, we study two populations of the tropical crab Goniopsis cruentata (Latreille 1803) that inhabit mangroves in different latitudes along the coast of Brazil. These mangroves are subject to different temperatures, rainfall regimes, and evaporation rates, and both temperature and rainfall are known to influence reproduction of $G$. cruentata (Cobo and Fransozo 2005; Lira et al. 2013). In addition, because $G$. cruentata is a semiterrestrial ectothermic species, it is likely to suffer an increased risk of desiccation in hotter and drier environments due to higher aerial exposure (Atkinson 1994; Allen et al. 2012). As a consequence, the biological traits of individuals inhabiting such environments might differ from their counterparts from cooler and more humid environments. We tested whether such divergence occurs on the basis of body size, sexual maturity, and allometric growth of a primary and a secondary sexual character (gonopod length and abdomen width in males and females, respectively).

\section{Materials and methods}

\section{Species and study localities}

Goniopsis cruentata is a crab species with a broad geographical distribution, occurring from Bermudas to Santa Catarina State, in the south of Brazil (Melo 1996). This species inhabits virtually every microhabitat in mangrove ecosystems, but it is most often found wandering in the substratum above the tide level (Melo 1996).

This study was carried out in two tropical mangroves, (1) in the estuary of the Jaguaribe River, Ceará State, and (2) in the Mundaú/Manguaba Estuarine Complex, Alagoas State, Northeast Coast of Brazil (Fig. 1). The two areas are $5^{\circ}$ of latitude apart from each other. In Ceará, the area of study is classified as semiarid (Araújo et al. 2012) and is characterized by lower rainfall, higher temperatures, and higher evaporation rates than mangroves from Alagoas (Table 1). The dry season starts in June and ends in January, and the rainy season starts in February and ends in May (Folhes et al. 2009). Harsh droughts, associated with

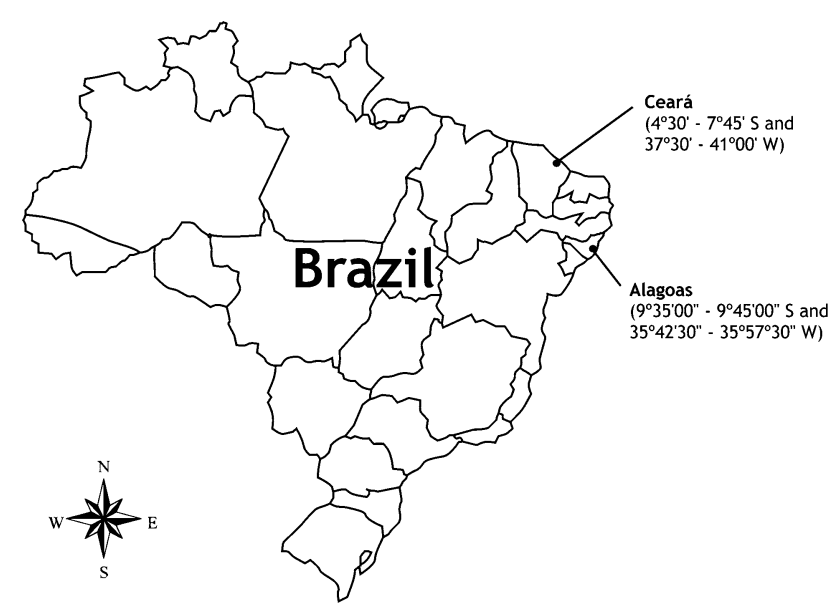

Fig. 1 Location of the study sites, Alagoas and Ceará States, Northeastern Coast of Brazil, with their respective geographical coordinates 
Table 1 Historical mean rainfall and temperature, and previous published evaporation data for the areas of study, Alagoas and Ceará, Northeastern Coast of Brazil

\begin{tabular}{lllll}
\hline Location & Rainfall $\left(\mathrm{mm}^{3}\right)$ & Temperature $\left({ }^{\circ} \mathrm{C}\right)$ & Evaporation $(\mathrm{mm})$ & Köppen \\
\hline Ceará & 770 & 28.5 & 3650 & Aw \\
Alagoas & 1500 & 24.9 & 1109 & Am \\
\hline
\end{tabular}

Rainfall and temperature data from Ceará refer to a 30-year period (from 1982 to 2012) and from Alagoas to a 12-year period (from 1998 to 2010). These were obtained from Araújo et al. (2012) for Ceará, and from Secretaria de Estado do Meio Ambiente e dos Recursos Hídricos, for Alagoas. Evaporation refers to accumulated annual evaporation rate. It was obtained from Folhes et al. (2009) for Ceará and from Oliveira and Kjerfve (1993), for Alagoas; however, the authors do not specify the period of data for which they obtained data from. In the case of Ceará, evaporation rate was estimated based on an evaporation rate of $10 \mathrm{~mm}$ per day. Köppen's classification is in accordance with Kottek et al. (2006) and Alvares et al. (2014)—for further details on Köppen's classification refer to these references

El niño-Southern Oscillation, are a regular phenomenon in Ceará (Folhes et al. 2009; Araújo et al. 2012). In Alagoas, the area of study is classified as a tropical humid region. The dry season starts in September and ends in February, and the rainy season starts in March and ends in August (Calado and Sousa 2003).

\section{Data acquisition and general procedures}

Here, we compare the data from two previously published studies, in Alagoas (Lira et al. 2013) and in Ceará (Lira et al. 2014). For further details on field or laboratory procedures, refer to these studies. Briefly, individuals of $G$. cruentata were sampled monthly from January to November 2011 in Ceará and from August 2007 to July 2008 in Alagoas. Crabs were haphazardly captured by hand and measured for carapace width $(\mathrm{CW})$, gonopod length (GL, males), and abdomen width (AW, females) with a caliper to the nearest $0.05 \mathrm{~mm}$. In Ceará, most of these crabs were measured in the field with only a few measured in the laboratory. Crabs with malformed or missing body limbs, or that had recently molted were not considered in the analysis to avoid bias due to inaccurate measurements. At each location, we obtained seven different measures of environmental factors per month for the period of study: temperature (mean, mean maximum, and mean minimum), rainfall, actual and potential evapotranspiration, and relative humidity. These data were provided by Instituto Nacional de Metereologia-INMET, Brazil.

\section{Statistical analysis}

To investigate differences in the abiotic factors between the two sampling locations, we performed a one-tailed Student's $t$ test. The same test was used to compare body sizes within sex between locations. Morphological maturity was defined as the breakpoint of the relationship between carapace width (predictor variable) and the primary and secondary sexual characters (response variables), which were gonopod length in males and abdomen width in females $(\log y=\log a+b \cdot \log x)$. This point was assessed using the program REGRANS (Pezzuto 1993). This breakpoint indicates that the pattern of growth of the gonopod and abdomen with respect to body size has changed (Hartnoll 1982; Pralon and Negreiros-Fransozo 2008), distinguishing the individuals as juveniles, on the left, and adults, on the right side of this point. Gonopod length and abdomen width are extensively demonstrated to be reliable indicators of morphological sexual maturity in crustaceans (Hartnoll 1982; Lira and Calado 2013).

We evaluated the growth of the gonopod length and abdomen width relative to body size for juvenile and adult crabs of both sexes using a linear regression. The fit of the models was based on the coefficient of determination $\left(R^{2}\right)$. The type of the growth was evaluated based on the slope (b) of each relationship: isometric growth $(b=1)$, implying the body part grows at the same rate as the whole body, negative allometric $(b<1)$, meaning that the body part grows slower than the body, and positive allometric growth $(b>1)$, when the body part grows faster in relation to the body (Hartnoll 1982). The difference of the slope from the reference value 1 was determined by its standard error (SE). To evaluate differences in relative growth of gonopod length and abdomen width within sex, we compared this growth between juveniles and between adults from Alagoas and Ceará. To do so, we performed an analysis of covariance (ANCOVA) with gonopod length and abdomen width as the response variables, carapace width as the continuous predictor variable, and location as the categorical predictor variable. This comparison was also conducted between juveniles and adults of each sex in both localities to indicate whether the pattern of relative growth differs between juvenile and adults. This allowed us to test the reliability of REGRANS at estimating size at sexual maturity. We also evaluated the intercept (a) of regression lines, when applicable. This was done because in some cases differences between regression lines cannot be detected by the slope but by the intercept (Bonduriansky 2007; Egset et al. 
2011). Differences in the intercept value reflect differences in trait size relative to body at the population mean with a constant slope (Egset et al. 2011), indicating that the relative growth of a trait relative to the whole body changes between the juvenile and the adult phase. Because it is a parameter that changes with data transformation (for example, log-transformed data), we obtained the value of the intercept from the regression lines for the raw data.

The analyses were performed with a significance level of $5 \%$. Data and the residuals were analyzed for normality using a Shapiro-Wilk test, and homogeneity of variance, using a Levene test. We also visually inspected the homogeneity of residuals as recommended by Quinn and Keough (2002). For the analysis of relative growth, data were log-transformed to meet the assumptions of normal distribution, homogeneity of variance, and homogenous distribution of residuals. Statistical analyses were performed using $\mathrm{R}$ software ( $\mathrm{R}$ Development Core Team 2012).

\section{Results}

Ceará, the northward location, presented higher temperatures and potential evapotranspiration than the southward location, Alagoas, for the period of study in each location (Table 2). On the other hand, rainfall, actual evapotranspiration, and relative humidity did not differ between these locations during the study periods-although it seems Ceará tends to have less rainfall and humidity than Alagoas given the marginal significant $p$ values (Table 2). Temperature and rainfall historical data from Ceará (30 years) and Alagoas (12 years) suggest that Ceará is warmer and has less rainfall than Alagoas, supporting the annual pattern which was found during the period of study in each location as commented above. Moreover, previous data indicates that Ceará has higher evaporation rates than Alagoas (Table 1).
Both males and females from Ceará were larger than their counterparts from Alagoas (males-Alagoas: $28.66 \pm 6.72 \mathrm{~mm}$, Ceará: $31.19 \pm 8.23 \mathrm{~mm}, t_{(978)}=-5.30$, $p<0.001$; females-Alagoas: $27.71 \pm 5.92 \mathrm{~mm}$, Ceará: $\left.29.89 \pm 6.75 \mathrm{~mm}, \quad t_{(942)}=-5.26, \quad p<0.001\right) \quad$ (Fig. 2). Moreover, both sexes reached larger maximum sizes in Ceará than their counterparts from Alagoas (males-Alagoas: $45.35 \mathrm{~mm}$, Ceará: $48.50 \mathrm{~mm}$; females-Alagoas: $43.45 \mathrm{~mm}$, Ceará: $44.30 \mathrm{~mm}$ ).

Size at morphometric maturity was larger in males $(28.15 \mathrm{mmCW})$ and females $(30.0 \mathrm{mmCW})$ from Ceará in comparison with males $(22.17 \mathrm{mmCW})$ and females (24.8 mmCW) from Alagoas (Figs. 3, 4). The relative growth of the gonopod length and the abdomen width on body size differed between juveniles and adults within each sex but not in females from Alagoas (Alagoas-males: $F_{1490}=423.53, \quad p<0.001, \quad$ females: $F_{1369}=1.26$, $p=0.26 ; \quad$ Ceará-males: $F_{1405}=91.01, \quad p<0.001$, females: $\left.F_{1388}=44.30, p<0.001\right)$. We then considered size at maturity with regard to the intercept of the regression lines; given that the intercept differed between juveniles $(-4.643 \pm 1.146$, intercept $\pm \mathrm{SE})$ and adults $(-7.129 \pm 0.785)$, we then considered the size at maturity of females from Alagoas as a reliable estimation.

The relative growth of the gonopod length and abdomen width was positive allometric for the majority of cases, except for the gonopod length of adult males from Ceará, which showed a negative allometric growth (Table 3). The gonopod growth on body size differed between juveniles and also between adults from Alagoas and Ceará (juveniles: $F_{1231}=40.12, p<0.001$; adults: $F_{1664}=40$. 36, $p<0.001$; ANCOVA, interaction carapace*location), in which a steeper positive allometric growth was observed in males from Alagoas. This was even more pronounced for juveniles, which presented a gonopod length growing $30 \%$ faster than that of their counterparts from Ceará (difference of $30 \%$ between slopes, Table 3 ). In females, the abdomen growth also differed between juveniles and between adults
Table 2 Mean values $( \pm \mathrm{SD})$ of abiotic factors for the period of study in Alagoas and Ceará States, Northeast Coast of Brazil

\begin{tabular}{lcccc}
\hline & Alagoas & Ceará & $t$ test & $p$ \\
\hline Minimum temperature $\left({ }^{\circ} \mathrm{C}\right)$ & $21.95 \pm 0.43$ & $22.77 \pm 0.89$ & $t_{(20)}=-2.75$ & $0.006^{*}$ \\
Maximum temperature $\left({ }^{\circ} \mathrm{C}\right)$ & $30.65 \pm 1.08$ & $32.54 \pm 1.55$ & $t_{(20)}=-3.31$ & $0.002^{*}$ \\
Mean temperature $\left({ }^{\circ} \mathrm{C}\right)$ & $25.82 \pm 0.87$ & $27.01 \pm 0.65$ & $t_{(20)}=-3.62$ & $<0.01^{*}$ \\
Rainfall $\left(\mathrm{mm}^{3}\right)$ & $217.7 \pm 230.6$ & $103.0 \pm 117.5$ & $t_{(21)}=1.48$ & 0.07 \\
Actual evapotranspiration $(\mathrm{mm})$ & $80.43 \pm 48.6$ & $83.22 \pm 63.32$ & $t_{(20)}=-0.11$ & 0.45 \\
Potential evapotranspiration $(\mathrm{mm})$ & $115.89 \pm 39.6$ & $141.97 \pm 6.20$ & $t_{(20)}=-2.16$ & $0.021^{*}$ \\
Relative humidity $(\%)$ & $78.88 \pm 4.88$ & $74.82 \pm 8.05$ & $t_{(20)}=1.43$ & 0.084 \\
\hline
\end{tabular}

Data refer to the mean annual values of each environmental parameter

$t$ value is presented along with its degrees of freedom (DOFs) between parentheses

$*$ Indicates significant values $(p<0.05)$ 


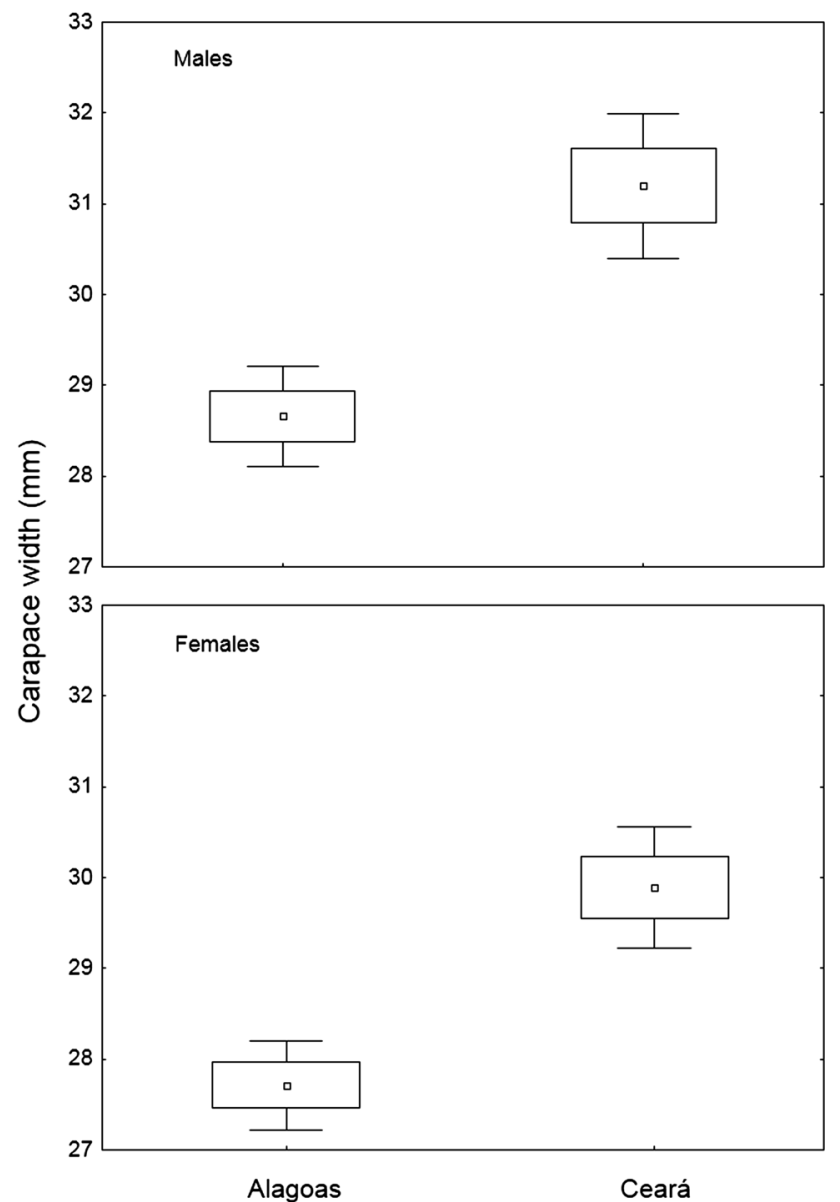

Fig. 2 Goniopsis cruentata. Mean body sizes of males and females for Alagoas and Ceará. White dots represent the mean values, the boxes the mean \pm standard error, and the bars represent mean $\pm 2 *_{\text {- }}$ standard error. These data refer to the total number of males and females sampled in each location (males: 494 in Alagoas and 409 in Ceará; females: 373 in Alagoas and 392 in Ceará)

(juveniles $-F_{1331}=6.33, p<0.001 ;$ adults $-F_{1454}=4$. 65, $p<0.031$; ANCOVA, interaction carapace*location). However, a clear pattern of growth as the one found in males was not observed: The abdomen grew markedly more relative to body size in juvenile females from Ceará than in juveniles from Alagoas and grew more in adults from Alagoas than in adults from Ceará (Table 3).

\section{Discussion}

We show that individuals from the northern Ceará population that inhabit a drier and hotter environment are larger and have a larger size at maturity than their counterparts from the southern Alagoas population that inhabit a more humid and cooler environment. The gonopods of juvenile males from Ceará grow much less relative to body size than their counterparts from Alagoas. This suggests a need of a

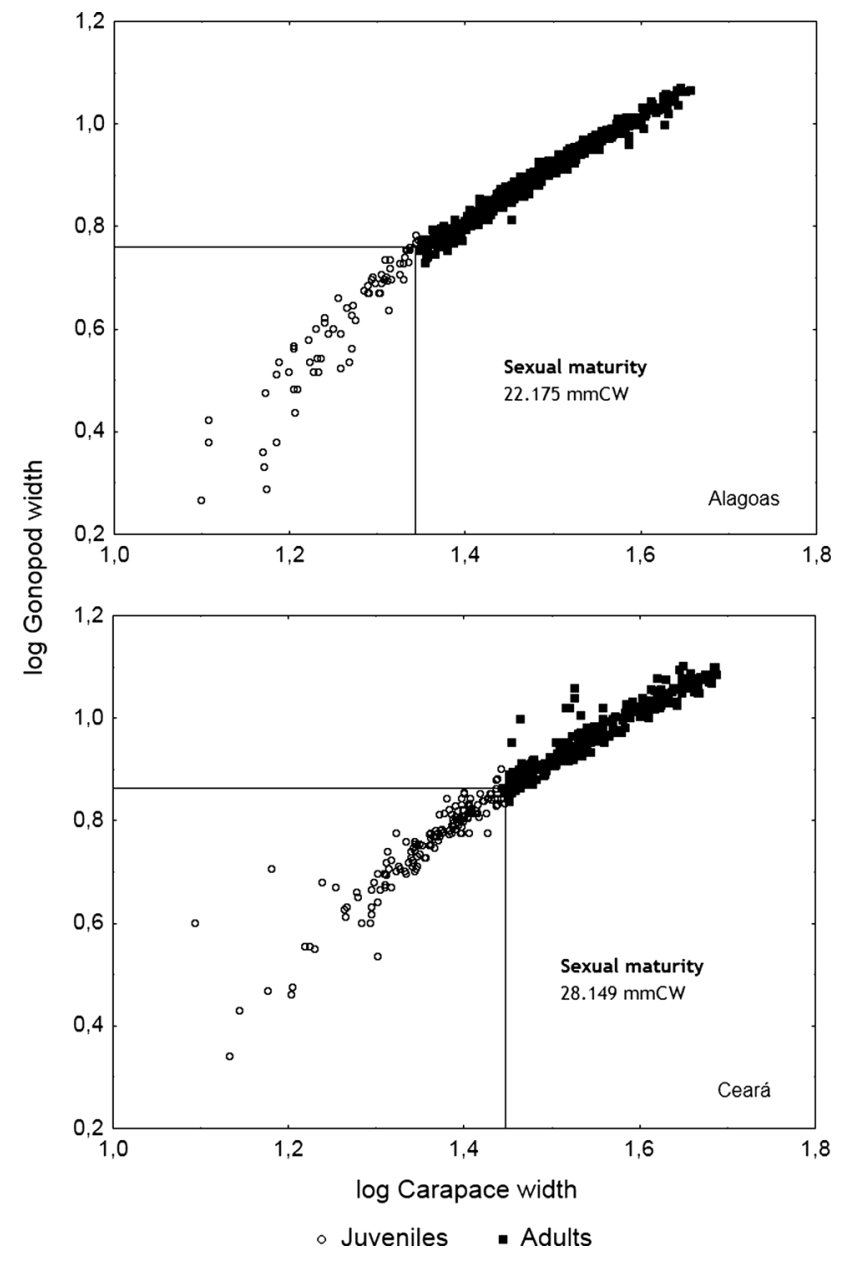

Fig. 3 Goniopsis cruentata. Size at sexual maturity of males from Alagoas and Ceará estimated through the relative growth of gonopod length $(\mathrm{mm})$ on body size $(\mathrm{mm})$. The lines indicate the breakpoint of such relationship, which indicates the size at sexual maturity. The white circles represent juveniles whereas black squares represent adults

pronounced growth in Alagoas population toward a minimum operative size or a favored gonopod size. In contrast, the relative growth of the abdomen width in females did not show such a pattern, and no clear trend between size at maturity and allometric growth of the abdomen was observed. This can occur because the abdomen undertakes only a secondary sexual function, i.e., embryo incubation; meanwhile, the gonopod is directly related to copulation and so might be under stronger selection than the abdomen, showing a somewhat defined pattern of allometric growth.

Individual body sizes observed here indicate that factors other than temperature play a role in determining geographic variation of body size in $G$. cruentata, which is consistent with findings with other organisms (Atkinson 1994; Olalla-Tárraga et al. 2009 and references therein). In our study, larger bodies were observed in the northern population inhabiting a hotter and drier environment, 


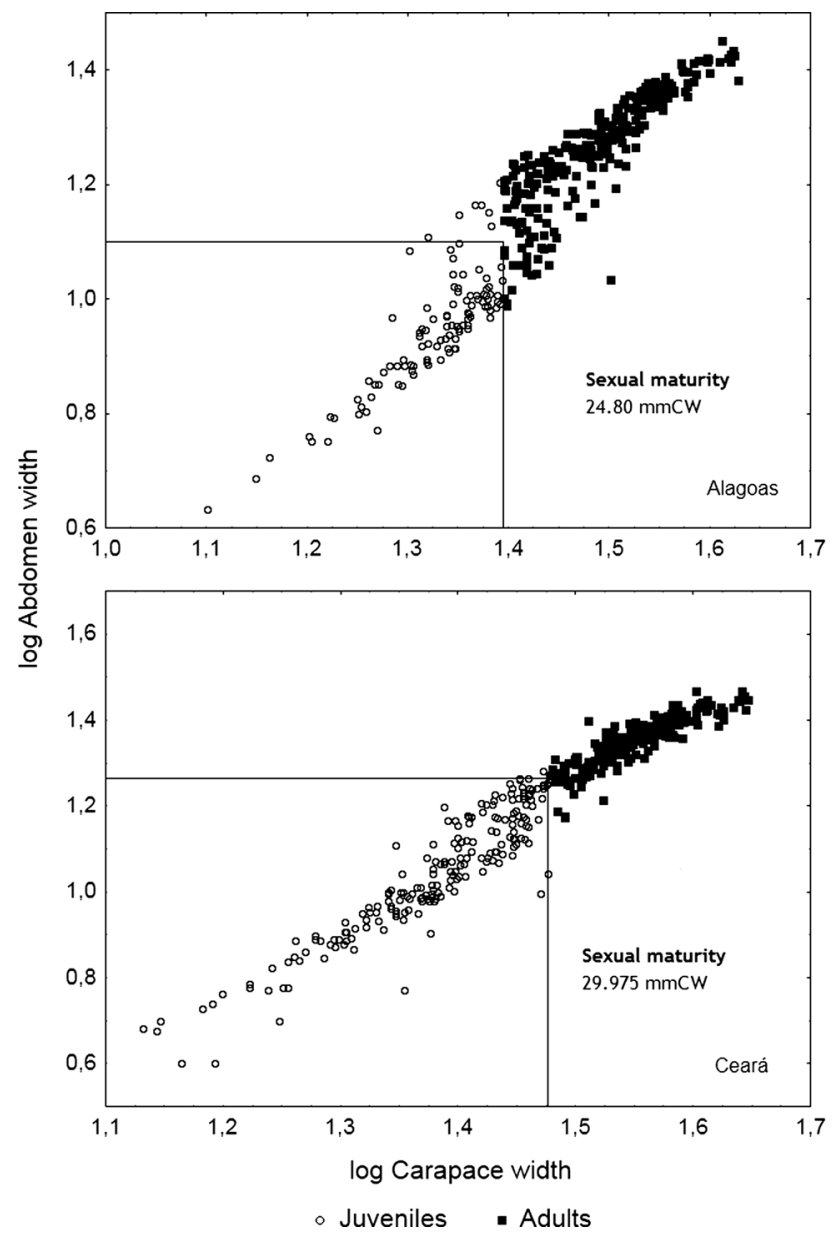

Fig. 4 Goniopsis cruentata. Size at sexual maturity of females from Alagoas and Ceará estimated through the growth of the abdomen width $(\mathrm{mm})$ relative to body size $(\mathrm{mm})$. The lines indicate the breakpoint of such relationship, which indicates the size at sexual maturity. The white circles represent juvenile individuals whereas black dots represent adult individuals

where desiccation risk is increased in comparison with the cooler and more humid environment. This is possibly an advantage to cope with such stressful conditions-larger bodies present a smaller surface area in relation to body volume than small individuals, which make them less prone to desiccation (Atkinson 1994; Gardner et al. 2011; Allen et al. 2012). This would be particularly important in extremely hot, dry environments where the rate of water loss is more pronounced (Gardner et al. 2011), which seems to occur more frequently on a temporal scale in Ceará because of recurring harsh droughts (Folhes et al. 2009; Araújo et al. 2012; also see maximum temperatures in Table 2). Such findings corroborate those of Yoder et al. (2007), who experimentally demonstrated that individuals of Uca pugilator are larger, and consequently less susceptible to desiccation, in a drier environment. However, the drier location in their study was southwards (Florida, USA), whereas the humid location was northwards (North Carolina, USA), the opposite trend of what we observed in the present study. Larger bodies can occur because of an increase in number or size of cells, or because of a prolonged but slower growth rate that leads to larger maximum body sizes (originally inferred to explain larger sizes at colder environments-Atkinson 1994; Angilletta et al. 2004b). Semiterrestrial crabs may present behavioral or physiological mechanisms to relieve desiccation stress (Macintosh 1988; Allen et al. 2012 and references therein). Accordingly, crabs can avoid exposure to extremely hot and dry conditions through reduced active behavior to prevent water loss. This could potentially restrict feeding times, resulting in reduced food intake in Ceará and a reduced growth rate (Hirose et al. 2013). However, our results contradict the general trend of larger body sizes toward high latitudes that has been reported found for many crustaceans (e.g., Jones and Simons 1983; Wehrtmann et al. 2012; Hirose et al. 2013).

Our results also show that sexual maturity differs between populations. We found that the large-bodied individuals from the northern, lower latitude population (Ceará) matured at larger sizes in comparison with the southern, higher latitude population (Alagoas), in both
Table 3 Results of logarithmized models describing the allometric relationships between gonopod length (GL, males) and abdomen width (AW, females) on carapace width $(\mathrm{mm})$ in juveniles and adults, for Alagoas and Ceará crabs

\begin{tabular}{llllllll}
\hline Sex & Stage & Location & $N$ & Slope $( \pm$ SE $)$ & Growth & $R^{2}$ & $p$ \\
\hline Male & Juvenile & Alagoas & 70 & $1.88( \pm 0.08)$ & + & 0.87 & $<0.001$ \\
& & Ceará & 165 & $1.32( \pm 0.04)$ & + & 0.86 & $<0.001$ \\
& \multirow{3}{*}{ Adult } & Alagoas & 424 & $1.03( \pm 0.01)$ & + & 0.98 & $<0.001$ \\
& & Ceará & 244 & $0.92( \pm 0.02)$ & - & 0.90 & $<0.001$ \\
\multirow{3}{*}{ Female } & \multirow{3}{*}{ Juvenile } & Alagoas & 108 & $1.54( \pm 0.09)$ & + & 0.70 & $<0.001$ \\
& & Ceará & 199 & $1.81( \pm 0.05)$ & + & 0.86 & $<0.001$ \\
& \multirow{3}{*}{ Adult } & Alagoas & 265 & $1.42( \pm 0.05)$ & + & 0.74 & $<0.001$ \\
& & Ceará & 193 & $1.24( \pm 0.05)$ & + & 0.78 & $<0.001$ \\
\hline
\end{tabular}

$N$ is the number of specimens. The slope $(b)$ is the inclination of the regression line that determines the type of allometric growth of the gonopod length and abdomen width in relation to carapace width: isometric growth (=), positive allometric $(+)$, and negative allometric growth $(-) . R^{2}$ is the coefficient of determination. SE is the standard error of the slope 
males and females. This pattern fits the prediction from life-history theory that individuals maturing at larger sizes reach larger mean body sizes than individuals maturing at smaller sizes (Atkinson 1994; Angilletta et al. 2004b), which is often related to a prolonged, slower growth (Morrison and Hero 2003; Angilletta et al. 2004a). This delay in size at maturity is likely to be favored because it often leads to an increase in fecundity owed to larger bodies, yet this benefit must compensate for a reduced survival rate until maturity is attained (Stearns 1989; Angilletta et al. 2004a, b). This hypothesis, however, lacks consistent evidences to explain geographic variation of sexual maturity (Angilletta et al. 2004b).

The allometric growth patterns that were observed in $G$. cruentata partially support our prediction that smaller size at maturity leads to a pronounced growth of primary/secondary sexual characters. In males, the gonopod did undertake a pronounced positive growth in juveniles from the population maturing at smaller sizes (Alagoas), suggesting that the individuals from this population must reach a minimum size prior to maturity or that a certain size is favored regardless of size at maturity. In other words, maturing at smaller sizes would select for a marked positive growth of the gonopods because of a shorter developmental time in comparison with delayed maturity. This can reflect the copulatory function of the gonopods, which is tightly associated with the female genitalia, the gonopores (Eberhard et al. 2009). Thus, the gonopod is potentially under strong selection for a size that would best fit the female genitalia. This favored size is necessarily a mean phenotype, since we observed a dramatic reduction in gonopod growth, from positive in juvenile to negative allometric growth or near isometry in adult males, which implies that such structure is undergoing stabilizing selection (Émond et al. 2010). This reduction in gonopod growth has been demonstrated previously for G. cruentata (Cobo and Fransozo 1998; Lira and Calado 2013; Lira et al. 2014), and is in accordance with the general pattern for male genitalia in a myriad of species (Eberhard et al. 2009).

On the other hand, the abdomen width showed a marked positive allometric growth relative to body size in juvenile females from the population maturing at a larger size, Ceará, which contradicts our prediction but corroborates the findings of Hirose et al. (2013). We suggest that this result indicates the need for a larger abdomen at maturity in this population, which allows for more offspring to be incubated at maturity since the number of eggs which is produced is dependent on the space available for incubation (Hartnoll 1982; Hines 1982). The greater reduction in the abdomen growth from juvenile to adult phase in this population may support this hypothesis. Yet, we lack more direct evidence to explain such divergence between populations. Moreover, we found that the abdomen width demonstrates a positive allometric growth throughout ontogenetic development in both populations, allowing for a safer incubatory chamber for the extruded eggs prior to their release (Hartnoll 1982). This broadening of the abdomen has been observed before for G. cruentata (Cobo and Fransozo 1998; Lira and Calado 2013; Lira et al. 2014), and is consistent with the general pattern among crustaceans (Hartnoll 1982; Lira and Calado 2013 and references therein). This indicates that the abdomen is under directional selection toward a larger phenotype (Émond et al. 2010; but see Bonduriansky 2007).

Our results show that geographic variation of biological aspects can occur in a set of related life-history traitsvariation in one trait can promote variation in others. In this study, geographic variation was associated with differences in body size, sexual maturity, and growth of reproductive traits. Overall, our findings provide further evidence that local conditions influence how biological traits vary geographically.

Acknowledgments We are grateful to Romina Ituarte, William Fernandes, Victor Frankel, Marisol Valverde, Caitlin Friesen, and two anonymous reviewers for providing useful comments to previous versions of this manuscript. The first author is also thankful to Conselho Nacional de Desenvolvimento Científico e Tecnológico- $\mathrm{CNPq}$ (process number 112334/2007-5) and Fundação Cearense de apoio ao Desenvolvimento Científico e Tecnológico-FUNCAp, Brazil, for the undergraduation' and master' scholarships granted, respectively.

\section{References}

Allen BJ, Rodgers B, Tuan Y, Levinton JS (2012) Size-dependent temperature and desiccation constraints on performance capacity: implications for sexual selection in a fiddler crab. J Exp Mar Biol Ecol 438:93-99. doi:10.1016/j.jembe.2012.09.009

Alvares CA, Stape JL, Sentelhas PC, Gonçalves JLM, Sparovek G (2014) Köppen's climate classification map for Brazil. Metereorol Z 22:711-728. doi:10.1127/0941-2948/2013/0507

Angilletta MJ, Niewiarowski PH, Dunham AE, Leaché AD, Porter WP (2004a) Bergmann's clines in ectotherms: illustrating a lifehistory perspective with sceloporine lizards. Am Nat 164:E168E183. doi:10.1086/425222

Angilletta MJ, Steury TD, Sears MW (2004b) Temperature, growth rate, and body size in ectotherms: fitting pieces of a life-history puzzle. Integr Comp Biol 44:498-509. doi:10.1093/icb/44.6.498

Araújo JMC Jr, Otero XL, Marques AGB, Nóbrega GN, Ferreira TO (2012) Selective geochemistry of iron in mangrove soils in a semiarid tropical climate: effects of the burrowing activity of the crabs Ucides cordatus and Uca maracoani. Geo-Mar Lett 32:289-300. doi:10.1007/s00367-011-0268-5

Atkinson D (1994) Temperature and organism size: a biological law for ectotherms? Adv Ecol Res 25:1-58

Bonduriansky R (2007) Sexual selection and allometry: a critical reappraisal of the evidence and ideas. Evolution 61:838-849. doi:10.1111/j.1558-5646.2007.00081.x

Calado TCS, Sousa EC (2003) Crustáceos do complexo estuarino/ lagunar Mundaú-Manguaba, Alagoas. FAPEAL, Maceió 
Cobo VJ, Fransozo A (1998) Relative growth of Goniopsis cruentata (Crustacea: Brachyura: Grapsidae), on the Ubatuba region, São Paulo, Brazil. Iheringia 84:21-28

Cobo VJ, Fransozo A (2005) Physiological maturity and relationships of growth and reproduction in the red mangrove crab Goniopsis cruentata (Latreille) (Brachyura, Grapsidae) on the coast of São Paulo, Brazil. Rev Bras Zool 22:219-223

Core Team R (2012) R: a language and environment for statistical computing. R Foundation for Statistical Computing, Vienna

Eberhard W, Rodriguez RL, Polihronakis M (2009) Pitfalls in understanding the functional significance of genital allometry. J Evol Biol 22:435-445. doi:10.1111/j.1420-9101.2008.01654.x

Egset CK, Bolstad GH, Rosenqvist G, Endler JA, Pelabon C (2011) Geographical variation in allometry in the guppy (Poecilia reticulata). J Evol Biol 24:2631-2638. doi:10.1111/j.1420-9101. 2011.02387.x

Émond KE, Sainte-Marie B, Gendron L (2010) Relative growth, lifehistory phases, and sexual maturity of American lobster (Homarus americanus). Can J Zool 88:347-358. doi:10.1139/ Z10-008

Folhes MT, Rennó CD, Soares JV (2009) Remote sensing for irrigation water management in the semi-arid Northeast of Brazil. Agric Water Manag 96:1398-1408. doi:10.1016/j.agwat. 2009.04.021

Gardner JL, Peters A, Kearney MR, Joseph L, Heinsohn R (2011) Declining body size: a third universal response to warming? Trends Ecol Evol 26:285-291. doi:10.1016/j.tree.2011.03.005

Hartnoll RG (1982) Growth. In: Bliss DE (ed) The biology of Crustacea: embryology, morphology and genetic. Academic Press, New York, pp 111-196

Hartnoll RG (1985) Growth, sexual maturity and reproductive output. In: Wenner AM (ed) Factors in adult growth. A.A. Balkema, Rotterdam, pp 101-123

Hartnoll RG (2006) Reproductive investment in Brachyura. Hydrobiologia 557:31-40. doi:10.1007/s10750-005-9305-6

Hines AH (1982) Allometric constraints and variables of reproductive effort in brachyuran crabs. Mar Biol 69:309-320. doi:10.1007/ BF00397496

Hines AH (1989) Geographic variation in size at maturity in brachyuran crabs. Bull Mar Sci 45:356-368

Hirose GL, Fransozo V, Tropea C, López-Greco L, NegreirosFransozo ML (2013) Comparison of body size, relative growth and size at onset sexual maturity of Uca uruguayensis (Crustacea: Decapoda: Ocypodidae) from different latitudes in the south-western Atlantic. J Mar Biol Ass UK 93:781-788. doi:10. 1017/S0025315412001038

Jones MB, Simons MJ (1983) Latitudinal variation in reproductive characteristics of a mud crab, Helice crassa (Grapsidae). Bull Mar Sci 33:656-670

Kingsolver JG, Huey RB (2008) Size, temperature, and fitness: three rules. Evol Ecol Res 10:251-268

Kottek M, Grieser J, Beck C, Rudolf B, Rubel F (2006) World Map of the Köppen-Geiger climate classification updated. Meteorol Z 15:259-263. doi:10.1127/0941-2948/2006/0130

Lardies MA, Arias MB, Bacigalupe LD (2010) Phenotypic covariance matrix in life-history traits along a latitudinal gradient: a study case in a geographically widespread crab on the coast of Chile. Mar Ecol Prog Ser 412:179-187. doi:10.3354/meps08694

Lira JJPR, Calado TCS (2013) Reproductive aspects and adaptive relative growth of the tropical crab Goniopsis cruentata. Anim Biol 63:407-424. doi:10.1163/15707563-00002422

Lira JJPR, Calado TCS, Araújo MSLC (2013) Breeding period in the mangrove crab Goniopsis cruentata (Decapoda: Grapsidae) in Northeast Brazil. Rev Biol Trop 61:29-38
Lira JJPR, Silva JRF, Rezende CF, Martins RP, Ferreira TO, Souza LP (2014) Population biology of the crab Goniopsis cruentata: variation in body size, sexual maturity, and population density. Anim Biol 64:383-394. doi:10.1163/15707563-00002453

Macintosh DJ (1988) The ecology and physiology of decapods of mangrove swamps. Symp Zool Soc Lond 59:315-341

Melo GAS (1996) Manual de identificação dos Brachyura (caranguejos e siris) do litoral brasileiro. FAPESP/Plêiade, São Paulo

Monaco CJ, Brokordt KB, Gaymer CF (2010) Latitudinal thermal gradient effect on the cost of living of the intertidal porcelain crab Petrolisthes granulosus. Aquat Biol 9:23-33. doi:10.3354/ ab00223

Morrison C, Hero JM (2003) Geographic variation in life-history characteristics of amphibians: a review. J Anim Ecol 72:270-279. doi:10.1046/j.1365-2656.2003.00696.x

Olalla-Tárraga MA, Diniz-Filho JAF, Bastos RP, Rodríguez MA (2009) Geographic body size gradients in tropical regions: water deficit and anuran body size in the Brazilian Cerrado. Ecography 32:581-590. doi:10.1111/j.1600-0587.2008.05632.x

Oliveira AM, Kjerfve B (1993) Environmental responses of a tropical coastal lagoons system to hydrological variability: MundaúManguaba, Brazil. Est Coast Shelf Sci 37:575-591. doi:10.1006/ ecss.1993.1074

Pezzuto PR (1993) Regrans: a "basic" program for an extensive analysis of the relative growth. Atlântica 15:93-105

Pralon BG, Negreiros-Fransozo ML (2008) Relative growth and morphological sexual maturity of Uca cumulanta (Crustacea: Decapoda: Ocypodidae) from a tropical Brazilian mangrove population. J Mar Biol Ass UK 3:569-574. doi:10.1017/ S0025315408000453

Queirós AM, Weetman A, McLay HA, Dobby H (2013) Geographical variation in size at the onset of maturity of male and female Norway lobster Nephrops norvegicus (L., Homarida: Decapoda) in Scottish waters. Fish Res 139:132-144. doi:10.1016/j.fishres. 2012.11.002

Quinn G, Keough M (2002) Experimental design and data analysis for biologists. Cambridge University Press, Cambridge

Shimada Y, Shikano T, Kuparinen A, Gonda A, Leinonen T, Merilä J (2011) Quantitative genetics of body size and timing of maturation in two nine-spined stickleback (Pungitius pungitius) populations. PLoS One 6:e28859. doi:10.1371/journal.pone. 0028859

Stearns SC (1976) Life-history tactics: a review of the ideas. Q Rev Biol 51:3-47. doi:10.1146/annurev.es.08.110177.001045

Stearns SC (1989) Trade-offs in life-history evolution. Funct Ecol 3:259-268

Terossi M, Torati LS, Miranda I, Scelzo MA, Mantelatto FL (2010) Comparative reproductive biology of two southwestern Atlantic populations of the hermit crab Pagurus exilis (Crustacea: Anomura: Paguridae). Mar Ecol 31:584-591. doi:10.1111/j. 1439-0485.2010.00387.x

Wehrtmann IS, Miranda I, Lizana-Moreno CA, Hernáez P, BarrantesEchandi V, Mantelatto FL (2012) Reproductive plasticity in Petrolisthes armatus (Anomura, Porcellanidae): a comparison between a Pacific and an Atlantic population. Helgol Mar Res 66:87-96. doi:10.1007/s10152-011-0250-7

Yoder JA, Tank JL, Rellinger EJ, Moore BE, Gribbins KM (2007) Differences in body size and water balance strategies between North Carolina and Florida populations of the sand fiddler crab, Uca pugilator. J Crust Biol 27:560-564. doi:10.1651/S-2795.1 